\title{
Isolation and Characterization of Pepsin-Solubilized Collagen from the Skin of Black Carp (Mylopharyngdon piceus)
}

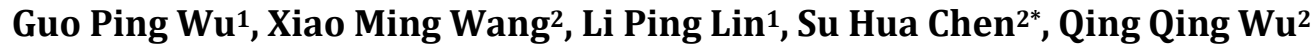 \\ ${ }^{1}$ College of Food Science and Engineering, Jiangxi Agricultural University, Nanchang, China \\ ${ }^{2}$ Key Laboratory of Jiangxi Province for Persistant Pollutants Control and Resources Recycle, Nanchang \\ Hangkong University, Nanchang, China \\ Email: ${ }^{*}$ trensuhua@163.com
}

Received 30 April 2014; revised 31 May 2014; accepted 13 June 2014

Copyright (C) 2014 by authors and Scientific Research Publishing Inc.

This work is licensed under the Creative Commons Attribution International License (CC BY).

http://creativecommons.org/licenses/by/4.0/

(c) (i) Open Access

\begin{abstract}
To make more effective use of underutilized resources, pepsin-solubilized collagen (PSC) was successfully extracted from the skin of black carp (Mylopharyngdon piceus) with a yield of $45.7 \%$ based on dry weight. The PSC comprising two identical $\alpha_{1}$-chains and one $\alpha_{2}$-chain with no disulfide bond was characterized as type $I$, and it contained 195 imino acid residues vs. 1000 amino acid residues. The collagen showed an absorption edge around $218 \mathrm{~nm}$, which was lower than the maximum absorption wavelength of other PSC. The denaturation temperature of PSC was $25.6^{\circ} \mathrm{C}$, which was lower than that of porcine collagen by approximately $11^{\circ} \mathrm{C}$. The isoelectric point (pI) was estimated to be 8.23 , and the collagen was soluble at an acidic $\mathrm{pH}$ as well as below $40 \mathrm{~g} / \mathrm{L} \mathrm{NaCl}$. It is thought that the high yield and stability of PSC from the skin of black carp warrant its application as a new source of collagen for industrial purposes.
\end{abstract}

\section{Keywords}

Pepsin-Solubilized Collagen (PSC), Characterization, Black Carp, Fish Skin

\section{Introduction}

Collagen is the predominant protein of animal body, comprising approximately $30 \%$ of total protein. It contributes to the unique physiological functions of connective tissues in skins, bones, cartilage, tendons, ligaments, blood vessels, and is associated with the toughness of mammalian muscle [1]. Because of its prevalence in mammals and excellent physical properties, collagen has been widely studied and applied in many industries,

${ }^{*}$ Corresponding author.

How to cite this paper: Wu, G.P., Wang, X.M., Lin, L.P., Chen, S.H. and Wu, Q.Q. (2014) Isolation and Characterization ofPepsin-Solubilized Collagen from the Skin of Black Carp (Mylopharyngdon piceus). Advances in Bioscience and Biotechnology, 5, 642-650. http://dx.doi.org/10.4236/abb.2014.57076 
including foodstuffs, cosmetics, and pharmaceuticals. At least 27 different types of collagen, named type IXXVII, have been reported, of which types I, II and III are the most abundant collagens which form fibrils responsible for tensile strength [2]. Particularly, type I collagen, being trimeric $\left.\left[\left(\alpha_{1}\right)_{2} \alpha_{2}\right)\right]$ and existing as triple helix, is found in all connective tissues [2].

Previously, collagen primary came from terrestrial animals such as the skin and bones of cows and pigs. However, outbreaks of bovine spongiform encephalopathy and the foot-and-mouth disease have sparked the search and development of a novel, alternative source of safe collagen. In addition, the collagen extracted from bovine sources cannot be used due to religious barriers. Therefore, the shift of collagen resource to aquatic animals has received increasing attention. Currently there are many reports on the isolation and characterization of collagen from marine and freshwater animals [3]. Fish industrial by-products such as skin, scales, fins and bones are rich in collagen. Extracting the collagen from these sources provides the aquaculture industry with a potential addition to its profit margin while addressing the increased pollution [4]. However, the collagen isolated from the leftovers is not enough for people to consume. So a new idea that isolates the collagen from underutilized source to achieve higher value should be proposed.

China is the largest freshwater fish producer in the world [5]. Black carp (Mylopharyngodon piceus), a freshwater fish of economic value, is one of the most abundant fish cultivated in China. Its skin exhibits some level of toughness, which may be associated with the collagen cross-links. However, no information on composition and biochemical properties of collagen from the skin of this species has been reported. Therefore, the aim of this study was to extract and characterize pepsin-solubilized collagen from the skin of black carp.

\section{Materials and Methods}

\subsection{Materials and Reagents}

The species of black carp used in this study was obtained alive from a local market in Nanchang, Jiangxi Province, China, with each fish weighing $1500 \pm 100$ g. Upon arrival, the skins were excised, washed with distilled water and extracted with $0.1 \mathrm{M} \mathrm{NaOH}$. The insoluble skin was then lyophilized.

Pepsin (10000 units/g) from the bovine gastric mucosa was obtained from Junsei Chemical Co. (Tokyo, Japan). Molecular weight calibration markers for gel filtration (10,000 - 250,000 Da) were purchased from BioRad (Hercules, CA, USA). Coomassie blue R-250 and N,N,N',N'-tetramethyl ethylene diamine (TEMED) were procured from Beijing Biosea Biotechnology Co. (Beijing, China). Sodium dedecyl sulfate and bovine serum albumin were obtained from Huiyi Biological Technology Co. (Beijing, China). All other reagents were all of analytical grade.

\subsection{Preparation of Pepsin-Solubilized Collagen}

The collagen was extracted as previously described by Zeng et al. [4] with some modifications. Unless otherwise indicated, all steps were performed at $4^{\circ} \mathrm{C}$. The skin samples were defatted with $10 \%$ of butyl alcohol at a ratio of 1:30 (dry mass/volume) for $24 \mathrm{~h}$ before being thoroughly washed with distilled water and lyophilized.

The lyophilized matter was suspended in $0.5 \mathrm{M}$ acetic acid and was digested with $10 \%(\mathrm{w} / \mathrm{v})$ pepsin for $48 \mathrm{~h}$. The mixtures were centrifuged at 20,000 $\mathrm{g} / \mathrm{min}$ for $45 \mathrm{~min}$ and the supernatants obtained were salted out by adding $\mathrm{NaCl}$ to a final concentration of $0.9 \mathrm{~mol} / \mathrm{L}$. The resultant precipitate was collected by centrifuging at $12000 \mathrm{~g} / \mathrm{min}$ for $20 \mathrm{~min}$. The pellet was then dissolved in $0.5 \mathrm{M}$ acetic acid and dialysed against 50 volumes of $0.1 \mathrm{M}$ acetic acid for $24 \mathrm{~h}$, followed by the dialysis in the same volume of distilled water for another $24 \mathrm{~h}$. The dialysate was freeze dried and was referred to as pepsin-solubilized collagen (PSC). The yield of PSC was calculated from the percentage of dry weight of PSC in comparison with the dry weight of the initial skin used. The extraction of collagens was performed in triplicate and the yield value was the average of triplicate determinations.

\subsection{Characterization of PSC}

\subsubsection{SDS-Polyacrylamide Gel Electrophoresis (SDS-PAGE)}

SDS-PAGE was performed by the method of Laemmli [6] with a slight modification. The PSC samples were dissolved in $0.1 \mathrm{M}$ acetic acid to reach a final collagen concentration of $1 \mathrm{mg} / \mathrm{mL}$, followed by the incubation at $95^{\circ} \mathrm{C}$ for $5 \mathrm{~min}$. A $10 \mu \mathrm{L}$ aliquot of prepared sample or protein marker was loaded per well into an $8.0 \%$ separa- 
tion gel and $4 \%$ stacking gel and subjected to electrophoresis at $4^{\circ} \mathrm{C}$ using a Mini-Protean Tetra Cell electrophoresis unit (Bio-Rad Laboratories Inc.). The gels were then stained with $0.1 \%(\mathrm{w} / \mathrm{v})$ Coomassie brilliant blue $\mathrm{R}-250$ dissolved in water-methanol-acetic acid (50:40:10, v/v/v). Gels were destained with a solution containing $30 \%(\mathrm{v} / \mathrm{v})$ methanol and $10 \%(\mathrm{v} / \mathrm{v})$ acetic acid.

\subsubsection{Amino Acid Analysis}

The amino acid analysis of PSC was performed following the method described by Pati et al. [3] with some modifications. The collagen sample was hydrolysed with $6 \mathrm{M} \mathrm{HCl}$ at $110^{\circ} \mathrm{C}$ for $24 \mathrm{~h}$. Then, the hydrolysates were analyzed on an amino acid analyzer (JLC-300 manufactured by Nihon Denshi Co., Ltd.).

\subsubsection{UV-Vis Measurement}

The ultraviolet absorption spectra of the prepared collagen were determined as previously described by Huang et al. [7] using a Hitachi U-3900 spectrophotometer.

\subsubsection{Fourier Transform Infrared Spectroscopy (FTIR)}

FTIR analysis was performed in a reflection configuration with a Bruker Vertex 70 spectrophotometer in the spectral range of 4000 to $500 \mathrm{~cm}^{-1}$ with a resolution of $2.0 \mathrm{~cm}^{-1}$. The lyophilized products were diluted approximately 5-fold with vacuum dried potassium bromide $(\mathrm{KBr})$ and pressed into pellets. The system was continuously purged with dry air. Reference spectra were recorded under identical conditions using the media (KBr) containing no protein as a control.

\subsubsection{Measurement of Zeta ( $\zeta$ ) Potential}

The $\zeta$-potential of the protein sample was measured using a Zetasizer Nano ZS (Malvern Instrument Ltd., Malvern, Worcestershire, UK) equipped with a $2 \mathrm{~mW}$ helium neon laser with an output of $633 \mathrm{~nm}$. Protein solutions were prepared in acetic acid $(0.5 \mathrm{M})$ to a final concentration of $0.5 \mathrm{mg} / \mathrm{ml}$ followed by stirring at $4^{\circ} \mathrm{C}$ for $12 \mathrm{~h}$. The $\mathrm{pH}$ was adjusted to different values with either $1.0 \mathrm{M}$ nitric acid or $1.0 \mathrm{M} \mathrm{KOH}$ using an Autotitrator (MPT-Z, Malvern, Multi Purpose Titrator, England). The isoelectric point (pI) was estimated from $\mathrm{pH}$ rendering a $\zeta$-potential reading of zero.

\subsubsection{Determination of the Denaturation Temperature by Viscometer}

The denaturation of collagen in solution was determined by changes in temperature-induced viscosity using an AND Vibro viscometer as previously described [3] with slight modifications. The viscometer was filled with $0.03 \%(\mathrm{w} / \mathrm{v})$ of collagen in $0.1 \mathrm{~mol} / \mathrm{l}$ acetic acid and incubated at $10^{\circ} \mathrm{C}$ for $30 \mathrm{~min}$. The temperature was then raised stepwise to $50^{\circ} \mathrm{C}$ at intervals of $1{ }^{\circ} \mathrm{C}$ and a heating rate of $0.5^{\circ} \mathrm{C} / \mathrm{min}$ and maintained for $10 \mathrm{~min}$ at each temperature. The fractional viscosity was calculated for each temperature as follows:

Fractional viscosity $=\left(\right.$ measured viscosity - viscosity $\left._{\min }\right) /\left(\right.$ viscosity $_{\max }-$ viscosity $\left._{\min }\right)$, where the viscosity was the specific viscosity $\left(\eta_{\mathrm{sp}}\right)$ and was calculated by the Equation $\left(\mathrm{t}-\mathrm{t}_{0}\right) / \mathrm{t}_{0}$, assuming the densities of the solution and solvent were the same ( $\mathrm{t}$ = efflux time of the collagen solution, $\mathrm{t}_{0}=$ efflux time of the solvent). The denaturation temperature $\left(T_{d}\right)$ was taken to be the temperature at which fractional viscosity was 0.5 .

\subsubsection{Effects of $\mathrm{pH}$ and $\mathrm{NaCl}$ on Collagen Solubility}

The solubility of PSC from the skin of black carp was determined in $0.5 \mathrm{M}$ acetic acid at various pH levels and $\mathrm{NaCl}$ concentrations as described by Huang et al. [7] and Zeng et al. [3]. The PSC sample was dissolved in 0.5 $\mathrm{M}$ acetic acid with gentle stirring at $4^{\circ} \mathrm{C}$ for $12 \mathrm{~h}$ to obtain final concentrations of 3 and $6 \mathrm{M}$. Approximately 8 $\mathrm{mL}$ of collagen solution ( $3 \mathrm{mg} / \mathrm{l}$ ) was transferred to a centrifuge tube and adjusted across the $\mathrm{pH}$ range from 1 to 10 with either $6 \mathrm{M} \mathrm{NaOH}$ or $6 \mathrm{M} \mathrm{HCl}$. The volume of sample solution was made up to $10 \mathrm{~mL}$ with distilled water previously adjusted to the same $\mathrm{pH}$ as the collagen sample solutions tested. Additionally, five $\mathrm{mL}$ of collagen solution (6 mg/L) in $0.5 \mathrm{M}$ acetic acid were mixed with $5 \mathrm{~mL}$ of cold $\mathrm{NaCl}$ in acetic acid of various concentrations to obtain final $\mathrm{NaCl}$ concentrations of $0 \mathrm{mg} / \mathrm{ml}$ to $60 \mathrm{mg} / \mathrm{ml}$.

All of these prepared solutions were stirred gently for $30 \mathrm{~min}$ and centrifuged at 12,000 rpm for $30 \mathrm{~min}$ at $4^{\circ} \mathrm{C}$. The protein contents in the supernatants were determined by the method previously described by Lowry et al. [8] using bovine serum albumin as a protein standard. 


\section{Results and Discussion}

\subsection{Isolation of PSC}

A pepsin-solubilized collagen (PSC) from the skin of black carp was purified to homogeneity through three purification procedures. As the non-collagen material was removed, pellets could be collected through centrifugation after the tested tissue was incubated with $10 \%$ (v/v) butyl alcohol successively. Each pellet was digested with acetic acid and pepsin solution, and the amount of soluble collagen was obtained. With this method, the PSC yield was $45.7 \%$ on the basis of dry weight. This result was similar to those of grass carp (46.6\%) [5], nautilus (50\%) and ocellate puffer (44.7\%) [9], but which is significantly higher than the yields from skins of balloon fish (19.5\%) [7], black drum (15.8\%) [10] and sheepshead seabream (29.3\%) [11]. The difference in the collagen yield may be due to the discrepancies in the construction of collagens among different species and preparation methods. For the collagen molecule, the two terminal ends are non-helical parts, which play an important role in the cross-linked structure. If there are many cross-linkages at the telopeptide region as well as at the inter-molecular cross-linkages, collagen in acidic solution has low solubility [4] [5].

The collagen sample obtained was examined by SDS-PAGE (Figure 1). The PSC consisted of $\alpha_{1}{ }^{-}$and $\alpha_{2}{ }^{-}$ chains with molecular weights estimated between 120-130 kDa. The cross-linked component, $\beta$-component, was also observed on SDS-PAGE. Therefore it should most likely be classified as type I collagen. If this collagen contained $\alpha_{3}$ chain, it could not be separated under the electrophoresis conditions employed [12]. Some $\beta$-component in the PSC might be cleaved into $\alpha$-components with the treatment of pepsin [13]. The SDS-PAGE pattern of PSC from the skin of black carp was essentially similar to that of PSC from the skin of cobia (Rachycentron canadum) [4].

\subsection{Amino Acid Composition}

The amino acid composition of PSC (expressed as the number of residues per 1000 amino acid residues) is shown in Table 1 and compared with those of from Rachycentron canadum skin PSC [4] and Aluterus monocerous skin PSC [14]. The PSC from the skin of black carp was rich in glycine (32.1\%), proline (12.7\%), alanine (12.4\%), glutamine (7.2\%) and hydroxyproline (6.8\%), which was similar to those of collagen composition from other fishes [4] [14]. In general, glycine occurs uniformly, at every third residue throughout most of collagen molecule. The PSC from the skin of black carp was found to be very low in methionine, isoleucine, tyrosine and histidine like other collagens. Also, the collagen consisted of proline and hydroxyproline, which are unique amino acids found in collagen.

The number of imino acid (proline and hydroxyproline) in PSC from the skin of black carp was 195 residues/1000 residues, which is lower than those of pig skin collagen (220 residues/1000 residues) and calf skin collagen (215 residues/1000 residues), but was similar with those of several fish skin collagens, including PSC from the skin of Rachycentron canadum (191 residues/1000 residues) [4], PSC from the skin of Aluterus mono-

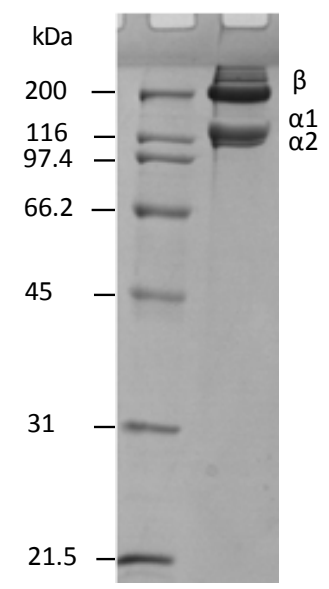

Figure 1. SDS-PAGE of the PSC purified from the skin of black carp. 
Table 1. Amino acid composition of the pepsin-solubilised collagen (PSC) from the skin of black carp (expressed as residues/1000 residues).

\begin{tabular}{|c|c|c|c|}
\hline Amido acid & B-PSC & C-PSC & U-PSC \\
\hline Asparagine & 47 & 45 & 47 \\
\hline Threonine & 26 & 23 & 27 \\
\hline Serine & 35 & 25 & 36 \\
\hline Glutamine & 72 & 69 & 72 \\
\hline Proline & 127 & 112 & 109 \\
\hline Glycine & 321 & 342 & 325 \\
\hline Alanine & 124 & 135 & 141 \\
\hline Cystine & 0 & 0 & 0 \\
\hline Valine & 24 & 25 & 21 \\
\hline Methionine & 12 & 14 & 12 \\
\hline Isoleucine & 11 & 12 & 7 \\
\hline Leucine & 20 & 21 & 16 \\
\hline Tyrosine & 2 & 2 & 2 \\
\hline Phenylalanine & 18 & 14 & 12 \\
\hline Lysine & 31 & 26 & 27 \\
\hline Histidine & 5 & 5 & 6 \\
\hline Arginine & 57 & 51 & 53 \\
\hline hydroxyproline & 68 & 79 & 83 \\
\hline total & 1000 & 1000 & 996 \\
\hline
\end{tabular}

B-PSC: pepsin solubilized collagen from the skin of black carp (Mylopharyngdon piceus), C-PSC: pepsin solubilised collagen from the skin of cobia (Rachycentron canadum), and U-PSC: pepsin solubilized collagen from the skin of unicorn leatherjacket (Aluterus monocerous).

cerous (192 residues/1000 residues) [14] and PSC from the skin of Ctenopharyngodon idella (186 residues/1000 residues) [5]. The higher imino acid content plays an important role in stabilizing helices, because the three alpha chains of PSC were held in place via hydrogen atoms and pyrolidine rings of proline and hydroxyproline, resulting in a strengthened triple helix. Therefore, the collagen helices of black carp skin might be less stable than those of mammalian skins, due to the lower imino acid content.

\subsection{UV Absorption Spectrum}

The optical absorption of PSC samples was measured by UV-vis diffuse reflectance spectrum, the results of which are shown in Figure 2. The PSC from the skin of black carp showed the maximum absorption at $218 \mathrm{~nm}$, which is in accordance with the PSC from cobia skin [4]. Generally, the maximum absorption wavelength of protein in the near ultraviolet region is $280 \mathrm{~nm}$, which is ascribed to the numbers of tyrosine and tryptophan residues. However, there is no obvious absorption for collagen in this region because the ratio of tyrosines in PSC from the black carp skin was only 2 residues per 1000 residues, and no tryptophan residues were present at all. The lower ratio may be related to the $\mathrm{C}=\mathrm{O}, \mathrm{COOH}$, and $\mathrm{CONH}_{2}$ groups in the polypeptide chains of collagen [4] [14].

\subsection{Fourier Transform Infrared Spectroscopy}

Figure 3 shows the FTIR spectra of PSC from the skin of black carp. As is shown, the main absorption bands are amide A $\left(3300 \mathrm{~cm}^{-1}\right)$, amide B $\left(2924 \mathrm{~cm}^{-1}\right)$, amide I $\left(1633 \mathrm{~cm}^{-1}\right)$, amide II $\left(1548 \mathrm{~cm}^{-1}\right)$ and amide III (1238 $\mathrm{cm}^{-1}$ ), which are similar to those of collagen from the skin of Rachycentron canadum [4]. The amide A band can be ascribed to $\mathrm{N}-\mathrm{H}$ [15], where a slight shift to lower wave numbers is observed comparing to non-collagens proteins $\left(3400-3440 \mathrm{~cm}^{-1}\right.$ ). When the $\mathrm{N}-\mathrm{H}$ group of a peptide is involved in a hydrogen bond, the position is shifted to lower frequencies, indicating that many of the $\mathrm{N}-\mathrm{H}$ groups of this collagen were involved in hydrogen 


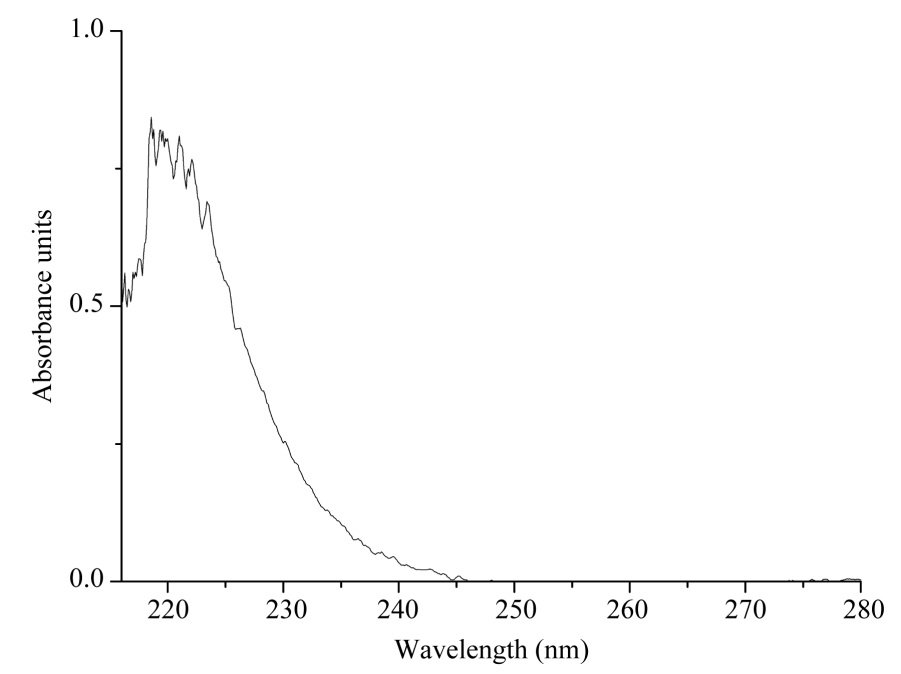

Figure 2. UV absorption spectrum of PSC from the skin of black carp.

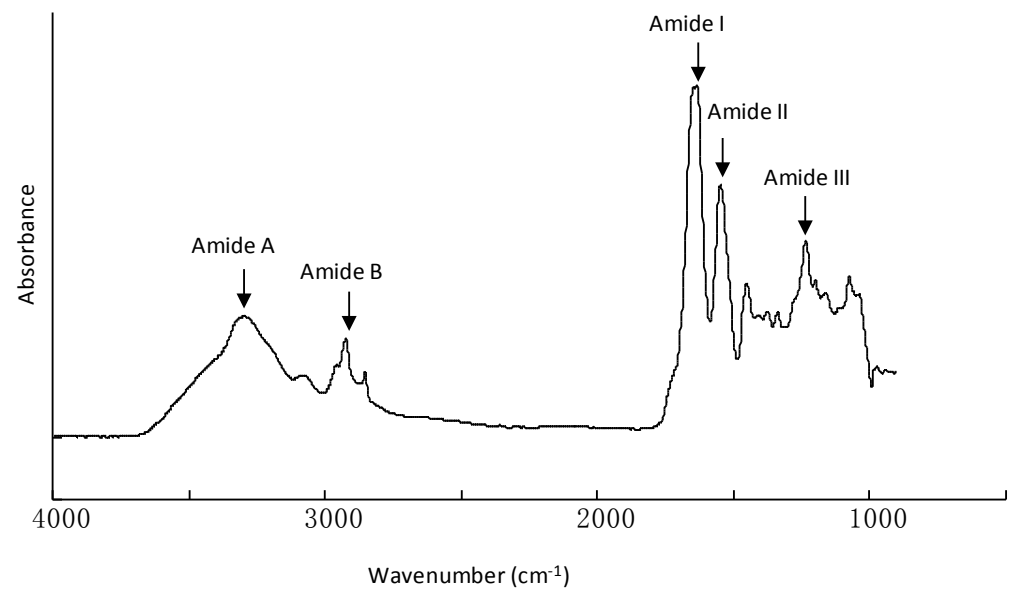

Figure 3. FTIR spectrum of PSC from the skin of black carp.

bonding. The amide B band position was observed at $2924 \mathrm{~cm}^{-1}$, which is commonly associated with an asymmetrical stretch of $\mathrm{CH}_{2}$ [16]. The peak near $1650 \mathrm{~cm}^{-1}$ is attributed to the carbonyl group $(\mathrm{C}=\mathrm{O})$ vibration and was designated as amide I. The absorption peak of PSC was observed at $1633 \mathrm{~cm}^{-1}$, which confirmed that the formation of hydrogen bonds between a stretch of $\mathrm{N}-\mathrm{H}$ groups and the $\mathrm{C}=\mathrm{O}$ group on Glycine (nearly $1 / 3$ ) contributes to the formation of the triple helix [17]. The amide II, with a characteristic wave number in the range of $1500-1600 \mathrm{~cm}^{-1}$, was primarily associated with the combination of the NH in-plane bend and the CN stretching vibration. The amide II of PSC was observed at $1548 \mathrm{~cm}^{-1}$. Generally, the shift to the lower wave number indicted the presence of hydrogen bonds in collagen. Amide III bands were observed at $1238 \mathrm{~cm}^{-1}$ for PSC, the peak of which is primarily associated with the combination peak between $\mathrm{N}-\mathrm{H}$ deformation and C-N stretching vibrations as well as the triple helical of collagen [15].

\subsection{Temperature Induced Change in Viscosity}

The denaturation temperature (Td) of PSC isolated from the skin of black carp was calculated using a plot of temperature-induced change in viscosity (Figure 4). The Td of PSC from the skin of black carp was $25.6^{\circ} \mathrm{C}$, which was similar to that of collagen from the skin of chub mackerel $\left(25.6^{\circ} \mathrm{C}\right)$ and bullhead shark $\left(25^{\circ} \mathrm{C}\right)[18]$, but was lower than that of collagen from terrestrial animals, including calf skin collagen $\left(40.8^{\circ} \mathrm{C}\right)$ and procine skin collagen $\left(37^{\circ} \mathrm{C}\right)[11]$. This result may be explained by the correlation of the Td of collagen with the body temperature of the organisms and the environment where they live. The thermal denaturation temperature of 


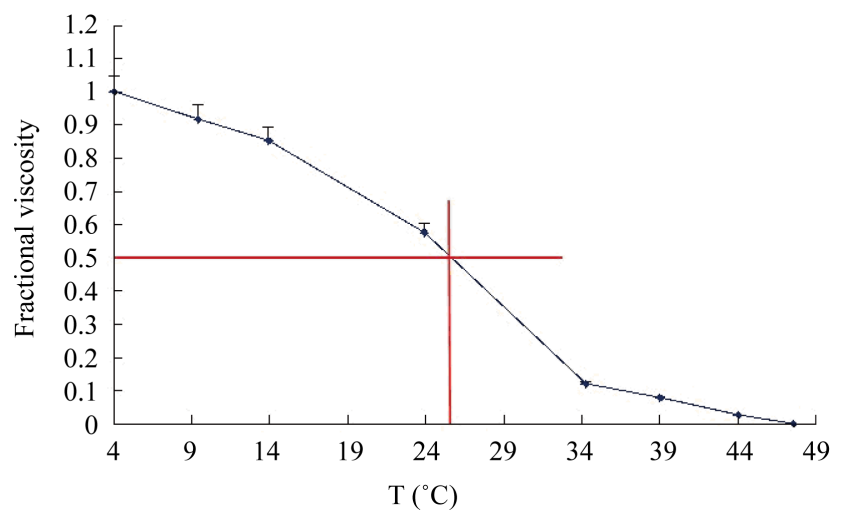

Figure 4. Thermal denaturation curve of PSC from the skin of black carp.

collagen from terrestrial species is correlated with the imino acid content (proline and hydroxyproline). The higher the imino acid content, the more stable the helical structure. The heat transformation of collagen induced the destruction of the triple-helical structure of collagen and generated random coils, which may result in a change of physical properties such as viscosity, sedimentation, diffusion, light scattering and optical activity. However, the denaturation temperature of collagens was also varied due to the differences in the extraction procedures and the analysis methods used [7].

\section{6. -Potential}

A pI of 8.23 was obtained for the PSC (date not shown), which is in conformity with most other collagens (pH 6 - 9) [19]. Vojdani [20] reported that when the negative charges balanced the positive charges, the protein in an aqueous system got a zero net charge at its isoelectric point (pI). The difference of collagen in pI might be attributed to the difference in acidic and basic amino acid residues, which was more likely governed by the removal of telopeptides by pepsin [21].

\subsection{Solubility of Collagen}

The effects of the $\mathrm{pH}$ and $\mathrm{NaCl}$ concentrations on the solubility of PSC from the skin of black carp are shown in Figure 5. In acidic $\mathrm{pH}$ ranging from 1 to 4 , the solubility of PSC increased as the $\mathrm{pH}$ rose and reached a maximum at $\mathrm{pH} 4$. A dramatic decrease in solubility occurred in the $\mathrm{pH}$ range between 4 and 6 and reached the minimum when the $\mathrm{pH}$ was increased to 8 . However, a slight increase in solubility was observed within the alkaline pH 9 as shown in Figure 5(a). The solubility of PSC at different pH is in agreement with the reports of Jongjareonrak et al. [10] and Zeng et al. [4]. It is known that at $\mathrm{pH}$ lower or higher than the $\mathrm{pI}$, the net charge residues of protein molecules are greater, and the solubility is increased by the repulsion forces between the chains. The precipitation and aggregation of collagen at a particular $\mathrm{pH}$ may be caused by the hydrophobic interaction of the collagen molecules and the high net charge of residues in protein molecules near the pI. Thus, the lowest solubility of PSC was obtained at $\mathrm{pH}$ around 8 which agreed with its pI 8.23 obtained from $\zeta$-Potential.

In Figure 5(b), a slight increase in the solubility of PSC in $0.5 \mathrm{M}$ acetic acid was observed in the presence of $\mathrm{NaCl}$ up to $10 \mathrm{mg} / \mathrm{ml}$, but the solubility of collagen was sharply decreased when the concentration of $\mathrm{NaCl}$ was increased to more than $10 \mathrm{mg} / \mathrm{ml}$. The greater solubility of PSC might be due to the partial hydrolysis of high molecular weight cross-linked molecules by pepsin. The decrease in solubility of PSC with increasing $\mathrm{NaCl}$ concentrations might be related to the impact of "salting out" [22]. These results of PSC solubility in different $\mathrm{pH}$ and $\mathrm{NaCl}$ concentrations may play an important role in its extraction and application.

\section{Conclusion}

PSC was successfully extracted from the skin of black carp with a significantly high yield. The PSC was characterized as type I collagen without a disulfide bond. The denaturation temperature of PSC was approximately $25.6^{\circ} \mathrm{C}$ and PSC was solubilized in an acidic $\mathrm{pH}$ rang, which could be lowered with higher concentrations of 


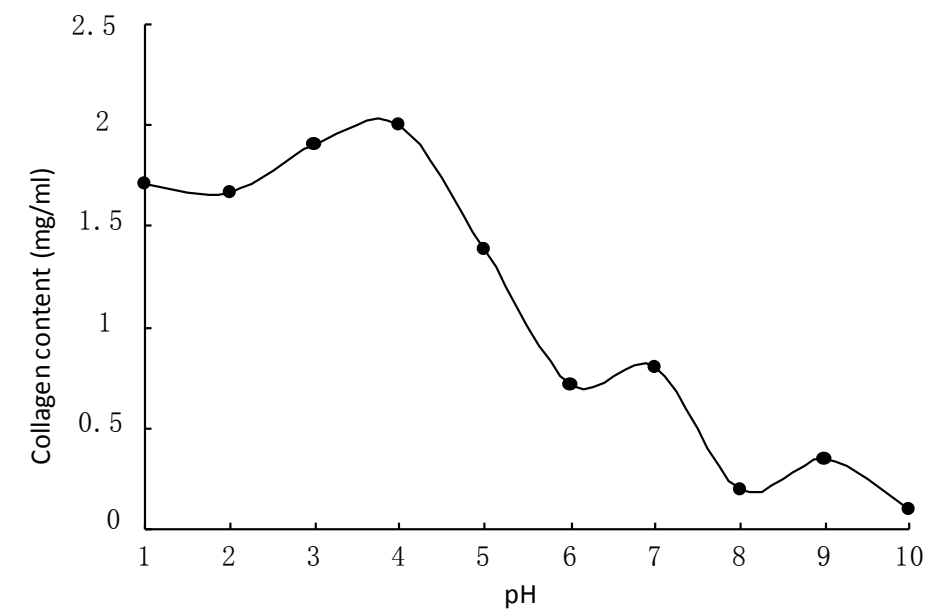

(a)

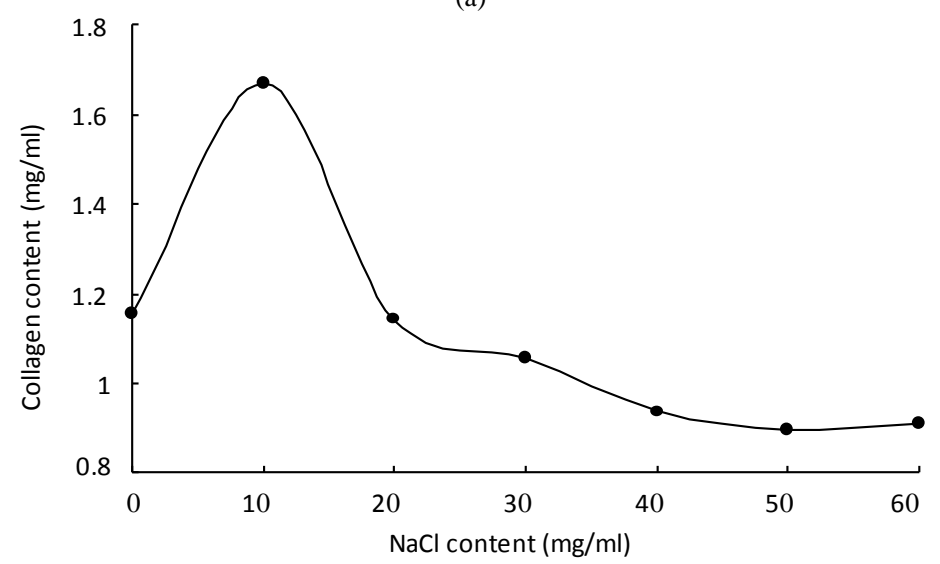

(b)

Figure 5. Solubility of PSC from the skin of black carp in $0.5 \mathrm{M}$ acetic acid at various $\mathrm{pH}$ (a) and $\mathrm{NaCl}$ content (b).

$\mathrm{NaCl}$. These results suggest that PSC isolated from the skin of black carp can be used as a potential alternative source to porcine collagen for some religions.

\section{Acknowledgements}

The work was financially supported by the National Natural Scientific Foundation of China (No. 41163004), the Science and Technology Research Foundation of Jiangxi (No. 20112BBF60018) and the Education Department of Jiangxi (GJJ12224), China.

\section{References}

[1] Nalinanon, S., Benjakul, S., Kishimura, H. and Osako K. (2011) Type I Collagen from the Skin of Ornate Threadfin Bream (Nemipterus hexodon): Characteristics and Effect of Pepsin Hydrolysis. Food Chemistry, 125, 500-507. http://dx.doi.org/10.1016/j.foodchem.2010.09.040

[2] Xiong, X., Ghosh, R., Hiller, E., Drepper, F., Knapp, B., Brunner H., and Rupp, S. (2009) A New Procedure for Rapid, High Yield Purification of Type I Collagen for Tissue Engineering. Process Biochemistry, 44, 1200-1212. http://dx.doi.org/10.1016/j.procbio.2009.06.010

[3] Pati, F., Adhikari, B. and Dhara, S. (2010) Isolation and Characterization of Fish Scale Collagen of Higher Thermal Stability. Bioresource Techonlogy, 101, 3737-3742. http://dx.doi.org/10.1016/j.biortech.2009.12.133

[4] Zeng, S.K., Yin, J.J., Yang, S.Q., Zhang, C.H., Yang, P. and Wu, W.L. (2012) Structure and Characteristics of Acid and Pepsin-Solubilized Collagens from the Skin of Cobia (Rachycentron canadum). Food Chemistry, 135, 1975-1984. 
http://dx.doi.org/10.1016/j.foodchem.2012.06.086

[5] Zhang, Y., Liu, W., Li, G., Shi, B., Yu, Q. and Wu, X. (2007) Isolation and Partial Characterization of Pepsin-Soluble Collagen from the Skin of Grass Carp (Ctenopharyngodon idella). Food Chemistry, 103, 906-912. http://dx.doi.org/10.1016/j.foodchem.2006.09.053

[6] Laemmli, U.K. (1970) Cleavage of Structural Proteins during the Assembly of the Head of Bacteriophage T4. Nature, 227, 680-685. http://dx.doi.org/10.1038/227680a0

[7] Huang, Y., Shiau, C., Chen, H. and Huang, B. (2011) Isolation and Characterization of Acid and Pepsin-Solubilized Collagens from the Skin of Balloon Fish (Diodon holocanthus). Food Hydrocolloids, 25, 1507-1513. http://dx.doi.org/10.1016/j.foodhyd.2011.02.011

[8] Lowry, O.H., Rosebrough, N.J., Farr, A.L. and Randall, R.J. (1951) Protein Measurement with Folin Phenol Reagent. Journal of Biological Chemistry, 193, 256-275.

[9] Nagai, T., Araki, Y. and Suzuki, N. (2002) Collagen of the Skin of Ocellate Puffer Fish (Takifugu rubripes). Food Chemistry, 78, 173-177. http://dx.doi.org/10.1016/S0308-8146(01)00396-X

[10] Jongjareonrak, A., Benjakul, S., Vesessangguan, W., Nagai, T. and Tanaka, M. (2005) Isolation and Characterization of Acid and Pepsin-Solubilized Collagen from the Skin of Brownstripe Red Snapper (Lutjanus vitta). Food Chemistry, 93, 475-484. http://dx.doi.org/10.1016/j.foodchem.2004.10.026

[11] Ogawa, M., Moody, M.W., Portier, R.J., Bell, J., Schexnayder, M.A., and Losso, J.N. (2003) Biochemical Properties of Black Drum and Sheephead Seabream Skin Collagen. Journal of Agricultural and Food Chemistry, 51, 8088-8092. http://dx.doi.org/10.1021/jf034350r

[12] Kimura, S. (1992) Wide Distribution of the Type I Collagen $\alpha 3$ Chain in Bony Fish. Comparative Biochemistry and Physiology, 102B, 255-260.

[13] Sato, K., Ebihara, T., Adachi, E., Kawashima, S., Hattori, S. and Irie, S. (2000) Possible Involvement of Aminotelopeptide in Self-Assembly and Thermal Stability of Collagen I as Revealed by Its Removal with Protease. Journal of Biological Chemistry, 275, 25870-25875. http://dx.doi.org/10.1074/jbc.M003700200

[14] Ahmad, M. and Benjakul, S. (2010) Extraction and Characterization of Pepsin-Solubilized Collagen from the Skin of Unicorn Leatherjacket (Aluterus monocerous). Food Chemistry, 120, 817-824. http://dx.doi.org/10.1016/j.foodchem.2009.11.019

[15] Zhang, M., Liu, W. and Li, G. (2009) Isolation and Characterization of Collagens from the Skin of Largefin Longbarbel Catfish (Mystus macropterus). Food Chemistry, 115, 826-831. http://dx.doi.org/10.1016/j.foodchem.2009.01.006

[16] Nagai, T., Suzuki, N. and Nagashima, T. (2008) Collagen from Common Minke Whale (Balaenoptera acurorostrata) Unesu. Food Chemistry, 111, 296-301. http://dx.doi.org/10.1016/j.foodchem.2008.03.087

[17] Matmaroh, K., Benjakul, S., Prodpran, T., Encarnacion, A.B. and Kishimura, H. (2011) Characteristics of Acid Soluble Collagen and Pepsin Soluble Collagen from Scale of Spotted Golden Goatfish (Parupeneus heptacanthus). Food Chemistry, 129, 1179-1186. http://dx.doi.org/10.1016/j.foodchem.2011.05.099

[18] Nagai, T. and Suzuki, N. (2000) Isolation of Collagen from Fish Waste Material—Skin, Bone and Fins. Food Chemistry, 68, 277-281. http://dx.doi.org/10.1016/S0308-8146(99)00188-0

[19] Foegeding, E.A., Lanier, T.C. and Hultin, H.O. (1996) Characteristics of edible Muscle Tissues. In: Fennema, O.R., Ed., Food Chemistry, Marcel Dekker Inc., New York, 902-906.

[20] Vojdani, F. (1996) Solubility. In: Hall, G.M., Ed., Methods of Testing Protein Functionality. St. Edmundsbury Press, London, 11-60. http://dx.doi.org/10.1007/978-1-4613-1219-2_2

[21] Kittiphattanabawon, P., Benjakul, S., Visessanguan, W., Nagai, T. and Tanaka, M. (2005) Characterization of Acid -Soluble Collagen from Skin and Bone of Bigeye Snapper (Priacanthus tayenus). Food Chemistry, 89, 363-372. http://dx.doi.org/10.1016/j.foodchem.2004.02.042

[22] Liu, D.S., Liang, L., Regenstein, J.M. and Zhou, P. (2012) Extraction and Characterization of Pepsin-Solubilised Collagen from Fines, Scales, Skin, Bones and Swim Bladders of Bighead Carp (Hypophthalmichthys nobilis). Food Chemistry, 133, 1441-1448. http://dx.doi.org/10.1016/j.foodchem.2012.02.032 
Scientific Research Publishing (SCIRP) is one of the largest Open Access journal publishers. It is currently publishing more than 200 open access, online, peer-reviewed journals covering a wide range of academic disciplines. SCIRP serves the worldwide academic communities and contributes to the progress and application of science with its publication.

Other selected journals from SCIRP are listed as below. Submit your manuscript to us via either submit@scirp.org or Online Submission Portal.
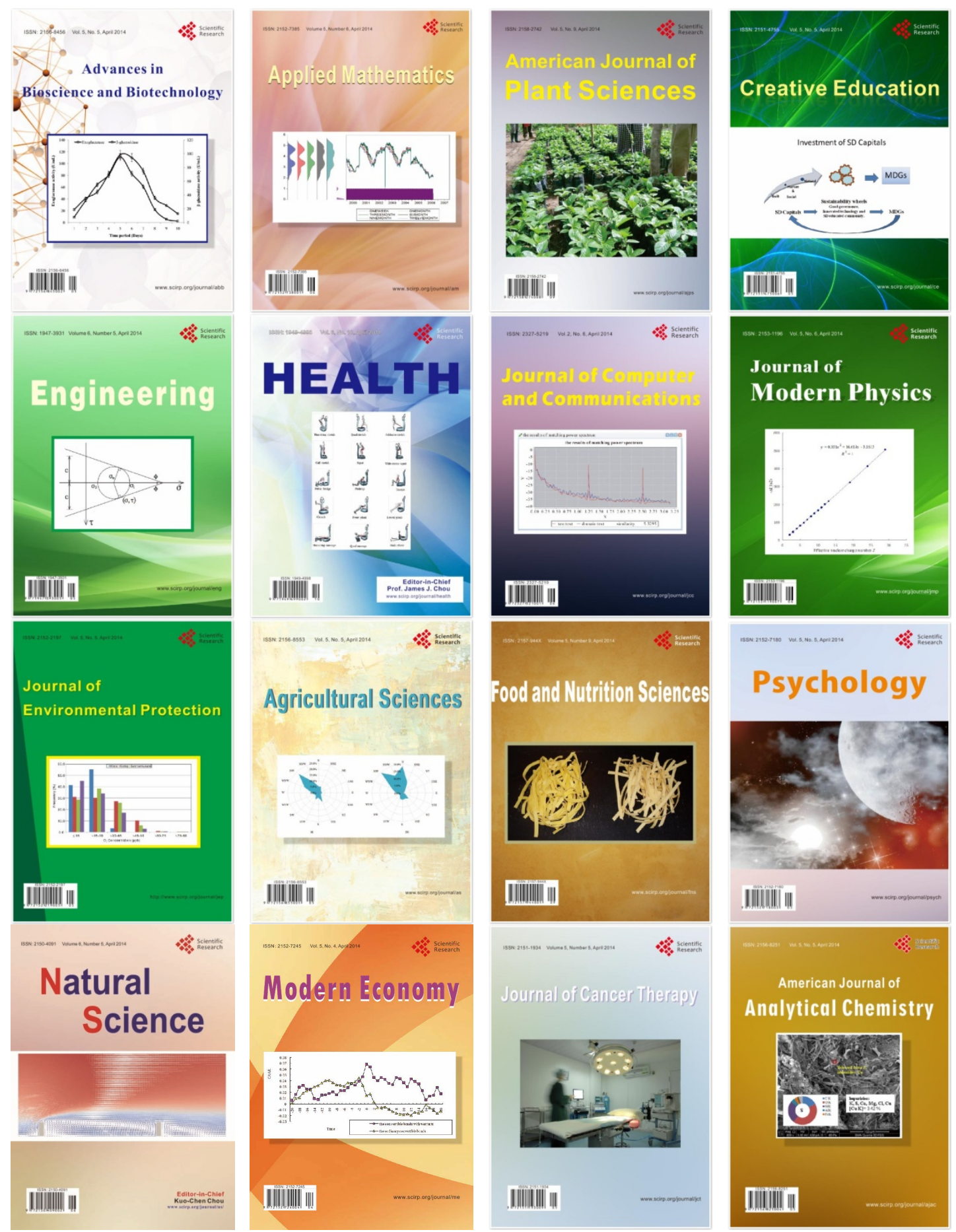